\title{
NHS DENTISTRY: PRE- AND POST-2006
}

1 April 2016 marks ten years since the current NHS dental contract was introduced.

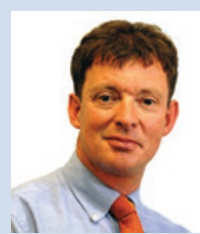

\section{Pre-2006 NHS} contract Nick Stolls, Oasis Dental Care, Harleston, Norfolk

Oh the halcyon days of the old dental contract. The days when you could open a practice where you wanted to, when you got paid for all the treatment you undertook and you weren't target driven. I've also worked for the past ten years under the current contract. Which one have I preferred? Without doubt the old contract.

When the Department of Health decided to cash limit NHS primary care dentistry both the profession and patients experienced a downturn in opportunities. Without registration the patients now can't be certain they can have continuity of care from their dentist. For the profession I have observed the decline in the career progression for my newly qualified colleagues. Under the old contract experience would be gained working as an associate in a practice until you felt sufficiently confident to take that step and buy a practice or even to set up a squat, taking on additional associates as the practice grew. There were no limitations on how many patients we could treat as we see with the current UDA system, no restriction as to where you could locate and no outside influences from commissioners. It was down to market forces and the ability of the practitioner to attract patients. Sadly since 2006 we have seen a decline in the status of 'performers', as they are now described. Colleagues have had to become 'career associates' because there simply aren't the opportunities to buy their own practices. Available practices rarely come to the market place and when they do they are usually snapped up by corporates. And don't get me started over the nonsense of having to buy practices through the partnership route, another new concept from the 2006 contract. So what is the effect of this restriction in practice availability? A race to the bottom of UDA values!

Many will remember the Admor chart: the resource dentists referred to under the fee per item' contract before computerisation. Far from being complicated there was a sense of financial justice for dentists, knowing that what treatments you completed, you got paid for.

UDAs were introduced as the new activity measure in 2006 with targets set for the year. But with those targets came the fear of over or underperformance, a restriction previously unheard of under the old contract.

Targets and treadmills are words that perhaps best describe the new contract, whilst freedom, flexibility, endeavour and aspiration may be the best way to describe the old contract with the nostalgia and fondness that comes with the passing of time. But my memory isn't what it used to be! Will things be better when the next contract is introduced? Maybe, but I'm not holding my breath.

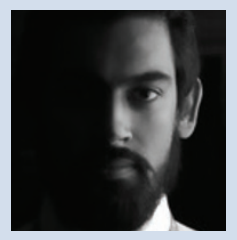

Post-2006 NHS contract Shiraz Khan, Locum SpR Restorative Dentistry/Associate Dental Surgeon @ShirazKhanage

Being a relatively contemporary dentist in the current UDA system allows for an open, honest and unbiased view of the current system. Of course, the fee-peritem system had its advantages and shortfalls; however, has the 'greatest reform of state-funded dental care since the inception of the NHS ${ }^{\prime 1}$ improved patient outcomes, and aided dentists to provide a more preventative care strategy?

Since 2006, there have been certain patterns of treatment. The number of complicated treatment plans has fallen, which does not necessarily correlate with improvements in oral health, but also the number of extractions as opposed to root treatment has also appeared to increase. ${ }^{2}$ It is difficult to ask a practitioner to commit to a treatment plan that requires the restoration of 12 teeth, two extractions and three root treatments for the same recompense as a single buccal glass ionomer restoration. I agree that offering cuspal protection, particularly for molar teeth post-root treatment, is often indicated due to increased probability of tooth fracture, but this should not be offered strictly to make the treatment financially viable for the practitioner.

Previously practitioners were remunerated for each item of treatment delivered, which led to over-treatment for a lot of our patients. However, strictly speaking the UDA system does not address this issue, particularly in low-needs, good oral health patients. Conversely, if the patient requires large amounts of treatment this should be provided. But conversations with colleagues and peers has allowed me to determine that occasionally 'splitting-treatment plans' has led to patients having been 'under-treated' within a specified band of treatment, whilst 'monitoring or watching other lesions'. These will then be re-addressed after three months to continue as a new course of treatment for the management of the remaining lesions. In my opinion, if an early enamel carious lesion can be managed with oral hygiene and dietary advice then this is better than committing that tooth to the restorative cycle. All treatment that is necessary should be undertaken as early as possible to ensure restorations are minimally destructive to the tooth. This being said, I am sure this is easier said than done, particularly in areas of high treatment need.

There is no incentive under the current system to deliver preventative care. Prevention is offered to each of my patients, whether this would be topical fluoride application in children, or dietary advice in patients with highly cariogenic diets, or smoking cessation advice in patients who have gone through pre-contemplation. However, this is not really a function of the current contract, rather, it is a function of the inherent responsibility to my patients.

Finally, the sheer variation in UDA values provides a grossly unfair advantage to dentists confined to specific areas. In theory, it is understandable that provision of services was increased and incentivised by providing practitioners with higher UDA values; however, for any two dentists providing the same treatment, under the NHS they will be remunerated differently.

In short, the current UDA system does not keep to its original promise in shifting towards preventativebased dental care, ${ }^{1}$ and in many circumstances is considered as another permutation of the previous 'treadmill'. Employing a preventative and conservative approach to any treatment/management that is delivered will always leave patients feeling cared for.

1. Davies B J B, Macfarlane F. Clinical decision making by dentist working in the NHS General Dental Services since April 2006. Br Dent J 2010; 209: E17.

2. House of Commons Health Committee. Dental services. London: House of Commons Health Committee, 2008. 